\title{
O ARQUIVO EM METAMORFOSE: RICARDO REIS É RECONSTRUÍDO POR SARAMAGO
}

Jorge Luiz Mendes Júnior

Mestrando UFJF

\begin{abstract}
RESUMO
O presente trabalho tem por finalidade sugerir uma hipótese de leitura da obra $O$ ano da morte de Ricardo Reis, de José Saramago, a partir da metáfora da ida do escritor ao arquivo, do qual ele recolhe elementos, para usá-los em sua obra. A partir de leituras de autores como Jacques Derrida e Michel Foucault, em Mal de arquivo: uma impressão freudiana e Arqueologia do saber, respectivamente, pretende-se mostrar que o autor não se limita a uma postura passiva frente ao arquivo, mas sempre lhe acrescenta algo. Na obra de Saramago supracitada, tentase mostrar isso mediante o processo de historicização e humanização sofrido pelo heterônimo de Fernando Pessoa. Mediante isso, estende-se a proposta de se repensar a noção de arquivo, conforme já sugerida por Derrida, não sendo este encarado como um "lugar” fechado, mas como uma instância sempre em aberto, sujeita a constantes visitações, modificações e acréscimos.
\end{abstract}

\section{PALAVRAS-CHAVE}

Arquivo, Ricardo Reis, José Saramago, Derrida, autor

Sugerindo-se que a obra literária não é apenas o resultado da mescla de um dado conteúdo com a genialidade artística de um autor, porém sem desconsiderar tais atributos, pode-se ter como hipótese de recepção e compreensão da mesma considerando-a como fruto de experiências, pesquisas, trabalho empírico por parte do autor.

Quando se considera a figura do autor como um pesquisador, um leitor de outras obras, pode-se tentar perceber as possíveis relações que ele talvez venha a estabelecer com suas fontes de pesquisa. Um olhar minucioso lançado sobre essas relações pode 
captar, não uma relação meramente passiva do autor frente a seus materiais de pesquisa, mas uma postura ativa, quando se nota que ele se apropria de determinados itens para reinventá-los em sua obra. Essas "fontes de pesquisa”, não importando sua natureza, serão tratadas neste trabalho pelo substantivo arquivo. Na tentativa de conceituar tal substantivo, alguns dicionários assim o fazem: "Lugar onde se recolhem e guardam documentos,"1 "lugar onde se guarda qualquer coisa”. ${ }^{2}$ Nessas duas acepções apresentadas, pode-se notar a ideia de o arquivo ser entendido como um "lugar" destinado a depósito de elementos. Segundo o filósofo francês Jacques Derrida, “a palavra e a noção de arquivo parecem, numa primeira abordagem, apontar para o passado, remeter aos índices da memória consignada, lembrar a fidelidade da tradição. ${ }^{3}$ Juntando-se as ideias de “depósito de documentos” e "registro do passado”, pode-se acabar por reforçar a noção geral preconcebida de o arquivo ser uma instância sempre fechada, apenas guardando registros de fatos passados, ficando estes, metaforicamente falando, como que inseridos em pastas ou gavetas, em permanente estado imutável. Contudo, como propõe Derrida, tal noção não dá conta de conceituar arquivo, conforme fica sugerido pela indagação: "Por que reelaborar hoje um conceito do arquivo?”4

A proposta de se encarar a postura ativa do escritor frente ao arquivo pode ser ilustrada mediante uma possível leitura da obra $O$ ano da morte de Ricardo Reis, de José Saramago. Já de início, como é possível inferir pelo título, pode ser visto um processo de “apropriação”, por parte de Saramago, da figura criada por Fernando Pessoa. O protagonista do romance e/ou heterônimo pessoano, Ricardo Reis, volta a Portugal em fins de 1935, após dezesseis anos “vivendo” exilado no Brasil, conforme deixou arquivado seu criador, Fernando Pessoa. Segundo o romancista:

Todo o discurso, escrito ou falado, é intertextual, e apeteceria mesmo dizer que nada existe que não o seja. Ora, sendo isto, creio, uma evidência do quotidiano, o que ando a fazer nos meus romances é a procurar os modos e as formas de tornar essa intertextualidade geral literariamente produtiva, se me posso exprimir assim, usá-las como uma personagem mais, encarregada de estabelecer e mostrar nexos, relações, associações entre tudo e tudo. ${ }^{5}$

\footnotetext{
${ }^{1}$ FERREIRA. Novo dicionário Aurélio da língua portuguesa.

${ }^{2}$ HOUAISS; VILLAR. Dicionário Houaiss da língua portuguesa.

${ }^{3}$ DERRIDA. Mal de arquivo: uma impresão freudiana, p. 47, 48.

${ }^{4}$ DERRIDA. Mal de arquivo: uma impresão freudiana, p. 7.

${ }^{5}$ SARAMAGO. Cadernos de Lanzarote, p. 610.
} 
É justamente através da intertextualidade com o arquivo, apoiada na possibilidade de ficcionalização oferecida pelo discurso literário, que Saramago consegue respaldo para se apropriar do elemento Ricardo Reis e reinventá-lo em seu romance: “(...) nome Ricardo Reis ... parece o princípio duma confissão, ... tudo o que é oculto se contém nesta linha manuscrita, agora o problema é descobrir o resto, apenas”. 6 Uma sugestão de leitura do trecho em questão é interpretar o verbo “descobrir” como uma falácia, pois não há o que ser descoberto, mas, sim, inventado. Por meio da invenção o autor constrói na narrativa o que neste trabalho se sugere como um processo de historicização e humanização do protagonista. Apropriando-se de registros de fatos históricos, mesclando-os com a ficção, o autor elabora o que se poderia traduzir num meio de ficcionalização da História e uma historicização do fictício.

A personalidade de Reis, conforme deixada registrada por seu criador, vincularse-ia a uma faceta clássica. Amante da cultura greco-romana, discípulo de Aberto Caeiro, Ricardo Reis não demonstra apego à vida social, optando pela simplicidade das coisas, sendo comedido, com aguda consciência da passagem do tempo e da inevitabilidade da morte, o que pode ser observado em alguns de seus versos: "Sábio é o que se contenta com o espetáculo do mundo"; "Tudo que cessa é morte”; "Amemonos tranqüilamente, pensando que podíamos,/ Se quiséssemos, trocar beijos e abraços e carícias,/ Mas que mais vale estarmos sentados ao pé um do outro/ Ouvindo correr o rio e vendo-o". 9

Na obra de Saramago, porém, a inserção de Ricardo Reis no mundo empírico, enquadrando-o num eixo espaço-temporal - necessidade conveniente ao gênero romance - leva-o, conforme já dito, a passar por um processo de humanização, o que pode ser percebido em dois planos: na relação de Reis com o mundo e na relação físicoafetiva com Lídia e Marcenda.

No que tange ao primeiro aspecto, vê-se Ricardo Reis, paulatinamente, envolvendo-se com os fatos histórico-sociais que o rodeiam, aos quais tem acesso via recursos midiáticos, mais especificadamente, os jornais: "Vai Ricardo Reis aos jornais,

\footnotetext{
${ }^{6}$ SARAMAGO. Cadernos de Lanzarote, p. 21.

${ }^{7}$ Disponível em: <http://www.citador.pt/poemas.php?op=10\&refid=200809030511>.

${ }^{8}$ Disponível em: <http://www.jornaldepoesia.jor.br/fp380.html>.

${ }^{9}$ Disponível em: <http://www.pensador.info/frase/NTI2OTEx/>.
} 
vai aonde sempre terá de ir quem das coisas do mundo passado quiser saber." ${ }^{10}$ As tensões vividas por Portugal sob a ditadura salazarista, bem como a atmosfera conflituosa pela qual passavam diversos outros países europeus no momento que antecedia o que viria a culminar na Segunda Guerra Mundial, gradualmente, sendo absorvidas como informações por Ricardo Reis, levam-no a transmutar sua postura epicurista para a de um sujeito que deixa mais aberta a exteriorização de seus sentimentos: "Lê Ricardo Reis os jornais e acaba por impor a si mesmo o dever de preocupar-se um pouco.”11 O ser que se contentava com o “espetáculo do mundo”, já tão envolvido nos fatos, já um elemento do mundo e da História, sente a necessidade de interagir com o meio, como pode ser notado no episódio em que se anuncia um comício. Dessa vez, Reis não quis esperar pelos jornais, mas “foi cedo para ter lugar, e de táxi para chegar mais depressa”. ${ }^{12}$ Tal mudança de comportamento é também referenciada pelo narrador: "para homem de natural tão pouco indagador, há interessantes mudanças em Ricardo Reis”. ${ }^{13}$ Essa mudança é o que pode ser entendida pelo que neste trabalho se sugere como processo de humanização pelo qual passa o protagonista. À medida que vai humanizando-se, Reis vai sendo sensibilizado pelas emoções, o que o torna diferente do que se apresenta em suas odes, a saber, um sujeito comedido, atento ao autodomínio. Essa atitude, no romance de Saramago, é substituída pelo extravasamento dos sentimentos, como pode ser exemplificado pelo episódio em que o navio Afonso de Albuquerque é bombardeado, e Reis, possivelmente movido pela empatia, “entra em casa, atira-se para cima da cama desfeita, escondeu os olhos para poder chorar à vontade". ${ }^{14}$

Num segundo plano, pode-se dizer que o processo de humanização de Ricardo Reis se processa mediante a interação físico-afetiva com o sexo oposto. No hotel em que se hospeda quando chega a Portugal, encontra uma criada homônima de uma de suas mais aclamadas musas, a saber, Lídia. Com ela, Reis estabelece uma relação quase que totalmente sexualizada, física, o que se diferencia da relação a distância que demonstrava ter com a Lídia de suas odes. As experiências sexuais já, em si mesmas,

\footnotetext{
${ }^{10}$ SARAMAGO. Cadernos de Lanzarote, p. 35.

${ }^{11}$ SARAMAGO. Cadernos de Lanzarote, p. 370.

${ }^{12}$ SARAMAGO. Cadernos de Lanzarote, p. 394.

${ }^{13}$ SARAMAGO. Cadernos de Lanzarote, p. 394.

${ }^{14}$ SARAMAGO. Cadernos de Lanzarote, p. 411.
} 
conferem-lhe traços humanos identitários, como o da necessidade de higiene sexual. Apesar de Ricardo Reis não identificar uma só semelhança entre a musa por ele idealizada e a criada do hotel, à exceção da igualdade nominal, ainda assim ela lhe suscita outras emoções: “Os olhos de Ricardo Reis encheram-se de lágrimas, umas de vergonha, outras de piedade... beijou-a muito, na boca ,... na vida há momentos assim.”15 Por meio da expressão destacada, pode-se sugerir uma constatação de trajetória humana. Reis ainda vive outra experiência com Marcenda, aquela que não é imarcescível, mas a quem, num ímpeto passional (o que mais uma vez o difere do sujeito comedido), chega a pedir em casamento.

As breves considerações feitas até aqui sugerem o processo de metamorfose pelo qual passa o heterônimo de Fernando Pessoa, no romance de Saramago. Tornar-se “humano” e um ser "historicizado” pode até mesmo ser entendido como um processo necessário para que se efetue o que já indicia o título: a morte de Ricardo Reis. Assim, vê-se que, ao apropriar-se do arquivo deixado por Pessoa, Saramago o modifica, acrescenta-lhe elementos novos. Tal processo permite que o arquivo não se feche. Para Michel Foucault, “o arquivo é, de início, a lei do que pode ser dito, o sistema que rege o aparecimento dos enunciados como acontecimentos singulares”. ${ }^{16}$ Visto assim, pode-se sugerir que o arquivo está sujeito a diversas modificações, acréscimos, suplementações, tal como atesta Jacques Derrida: “Incorporando o saber, o arquivista produz arquivo ... o arquivo aumenta, cresce, ... o arquivo não se fecha jamais. Abre-se para o Futuro.”17

\section{ABSTRACT}

The present work puts forth a reading of José Saramago's $O$ ano da morte de Ricardo Reis from a metaphor of the writer's going to the archive, from which he collects elements in order to use them in work. From readings of authors such as Jacques Derrida and Michael Foucault in Mal de arquivo and Arqueologia do saber, respectively, it is intended to show that the author does not restrain himself to a passive posture when facing the archive; on the other hand, he always adds something to it. In Saramago's aforementioned piece of work, I show that by

\footnotetext{
${ }^{15}$ SARAMAGO. Cadernos de Lanzarote, p. 356.

${ }^{16}$ FOUCAULT. A arqueologia do saber, p. 149.

${ }^{17}$ DERRIDA. Mal de arquivo: uma impressão freudiana, p. 88.
} 
means of the process of "historicization" and humanization underwent by Fernando Pessoa's heteroname. Through that, one can understand the rethinking of the notion of archive, as suggested by Derrida, not being a "closed place", but as an always open instance, apt to constant visitations, modifications and additions.

KEYWORDS

Archive, Ricardo Reis, José Saramago, Derrida, authorship

\section{REFERÊNCIAS}

DERRIDA, Jacques. Mal de arquivo: uma impressão freudiana. Trad. Claudia de Moraes Rego. Rio de Janeiro: Relume Dumará, 2001.

FERREIRA, Aurélio Buarque de Holanda. Novo dicionário Aurélio da língua portuguesa. 3. ed. Curitiba: Positivo, 2004.

FOUCAULT, Michel. A arqueologia do saber. Trad. Luiz Felipe B. Neves. Rio de Janeiro: Forense Universitária, 2000.

HOUAISS, Antônio; VILLAR, Mauro Salles. Dicionário Houaiss da língua portuguesa. Rio de Janeiro: Objetiva, 2001.

SARAMAGO, José. Cadernos de Lanzarote. São Paulo: Companhia das Letras, 1996. 